\title{
PENGARUH FREE CASH FLOW, FINANCIAL DISTRESS, DAN INVESTMENT OPPORTUNITY SET TERHADAP MANAJEMEN LABA
}

\author{
Sally Irawan ${ }^{1)}$, Prima Apriwenni ${ }^{2)^{*}}$ \\ ${ }^{1,2)}$ Program Studi Akuntansi, Institut Bisnis dan Informatika Kwik Kian Gie \\ Email : prima.apriwenni@kwikkiangie.ac.id
}

Diterima 16 Desember 2020 / Disetujui 25 Februari 2021

\begin{abstract}
Stakeholders pay attention to the earnings report, thus encouraging company managers to plan strategies to produce reports expected by stakeholders. Earnings management is one way that can be done. Managers can intervene the earnings management by increasing or decreasing profit in order to achieve a certain level of profit which benefits himself or the company. This study aims to determine the influence of free cash flow, financial distress, and investment opportunity set on earnings management. The research sample consisted of 11 infrastructure, utility, and transportation companies listed on the Indonesia Stock Exchange in 2014-2018 with the total sample of 55 data. This study used a purposive sampling method and was tested with SPSS 22.0 Software. The results show that the data have met the pooling test, classical assumptions and established criteria. The results of the $F$ test show that the earnings management variable is affected simultaneously by free cash flow, financial distress, and investment opportunity set variables. The $t$ test results show that the free cash flow and investment opportunity set have a significant positive effect on earnings management, whereas financial distress does not. In sum, there is enough evidence that free cash flow and investment opportunity set positively affect earnings management, but financial distress does not have enough evidence to influence earnings management.
\end{abstract}

Keywords: Earnings Management, Free Cash Flow, Investment Opportunity Set, Financial Distress.

\begin{abstract}
ABSTRAK: Laporan laba menjadi perhatian para stakeholders sehingga mendorong manajer perusahaan melakukan perencanaan strategi untuk menghasilkan laporan yang diharapkan stakeholder. Manajemen laba adalah salah satu cara yang dapat dilakukan. Intervensi manajer untuk melakukan manajemen laba dengan cara menaikkan atau menurunkan laba guna mencapai tingkat laba tertentu untuk menguntungkan dirinya sendiri atau perusahaan. Penelitian ini bertujuan untuk mengetahui pengaruh free cash flow, financial distress, dan investment opportunity set terhadap manajemen laba. Sampel penelitian ini adalah perusahaan infrastruktur, utilitas, dan transportasi yang terdaftar di Bursa Efek Indonesia periode 20142018. Total sampel yang digunakan adalah 11 perusahaan dengan data observasi yang diperoleh sebanyak 55. Teknik pengambilan sampel yang digunakan adalah non-probability sampling dengan menggunakan metode purposive sampling dan pengujian yang dilakukan dengan bantuan software SPSS 22.0. Hasil penelitian dari data yang digunakan, untuk uji pooling dan asumsi klasik telah lulus uji dan sudah memenuhi kriteria yang ditetapkan. Hasil uji F menunjukkan bahwa variable manajemen laba dipengaruhi secara simultan oleh variable free cash flow, financial distress, dan investment opportunity set. Dari hasil uji t memperlihatkan hasil bahwa free cash flow dan investment opportunity set mempunyai nilai signifikan positif terhadap manajemen laba, tapi untuk financial distress tidak mempunyai nilai signifikan terhadap manajemen laba. Kesimpulan dari penelitian ini adalah free cash flow dan investment opportunity set berpengaruh positif terhadap manajemen laba, sedangkan financial distress tidak berpengaruh terhadap manajemen laba.
\end{abstract}

Kata Kunci: Manajemen Laba, Free Cash Flow, Investment Opportunity Set, Financial Distress 


\section{Pendahuluan}

Salah satu perhatian yang penting dari pihak pemangku kepentingan seperti para kreditor, investor, pemerintah dan pihak lainnya adalah laporan keuangan yang diterbitkan oleh perusahaan. Laporan keuangan yang memperlihatkan laba dan kinerja perusahaan adalah laporan laba rugi yang berguna untuk para stakeholders dan investor yang digunakan dalam mempertimbangkan dan menaksir suatu investasi atau pun dalam membuat kontrak dan memperkirakan kelangsungan hidup suatu perusahaan. Perhatian para stakeholders lebih ditekankan pada laporan laba, sehingga hal ini memicu manajer untuk membuat strategi yang dapat membuat laporan seperti yang diharapkan para stakeholders dengan melakukan tindakan manajemen laba

Upaya umum yang dilakukan manajer perusahaan adalah mengubah laporan keuangan yang memberikan informasi kinerja dan kondisi perusahaan yang tujuan mengelabui stakeholders dengan cara melakukan manajemen laba. Ada 2 pandangan terhadap tindakan manajemen laba, satu pihak berpendapat bahwa manajemen laba adalah kecurangan, tapi di pihak lain berpendapat bahwa itu bukan bentuk kecurangan dengan alasan perubahan laporan keuangan yang dilakukan manajer masih dalam standar akuntansi, dengan cara menggunakan prosedur dan metode umum yang berlaku dan diakui akuntansi. Tindakan oppotunistik di dorong oleh keinginan untuk mendapatkan kompensasi dan bonus, penghindaran dari biaya politik dan kontrak utang, serta upaya mempengaruhi pasar modal, sehingga dilakukan manajemen laba dengan memanfaatkan fleksibilitas informasi yang ada (Perwitasari, 2014:432).

Teori keagenan (Jensen \& Meckling (1976:308) dapat menjelaskan manajemen laba dilakukan karena ada conflict of interest antara kepentingan pemilik perusahaan (principal) yang tidak sejalan dengan manajemen perusahaan (agent). Tuntutan tanggung jawab membuat keputusan untuk mendapatkan profitabilitas yang optimal bagi principal dengan cara menghasil sejumlah laba yang besar ada pada pihak manajemen perusahaan (agent), sehingga mendorong dilakukannya tindakan manajemen laba. Manajer sebagai agent disisi lain juga perlu untuk memenuhi kebutuhan psikologi dan ekonominya sendiri secara maksimal. Sehingga agent mungkin tidak terus dapat bertindak secara baik untuk kepentingan pemilik (principal).

Salah satu kasus manajemen laba yaitu pada PT Garuda Indonesia Tbk sebuah perusahaan BUMN yang termasuk sektor infrastruktur, utilitas, dan transportasi. Perusahaan ini pada tahun 2018 dalam laporan keuangan telah melakukan manipulasi terhadap net income sebanyak Rp 11,33 miliar (USD 809,84 ribu), dimana pada tahun sebelumnya mengalami rugi yang cukup besar (USD 216,5 juta). Ternyata pada tahun 2018 pendapatan yang diakui adalah pendapatan yang belum boleh diakui karena uang sebesar USD 239,94 juta karena masih dalam bentuk kontrak dengan PT MAT (www.cnnindonesia.com). Selain itu, terdapat kasus manajemen laba PT INVS (Inovisi Infracom) pada sektor yang sama. Pada laporan keuangan 2014 periode September ditemukan ketidak samaan oleh BEI dan dalam laporan keuangan tersebut ada salah saji sebanyak delapan item. Hal ini mengakibatkan perdagangan saham perseroan disuspensi oleh BEI dan akhirnya berujung pada delisting saham disebabkan perbaikan tidak dilakukan oleh perusahaan (www.economy.okezone.com). Kasus ini yang mendasari penulis untuk melakukan penelitian mengenai pengaruh-pengaruh yang dapat mengakibatkan terjadinya manajemen laba, khususnya pada sektor infrastruktur, utilitas, dan transportasi karena selama ini belum pernah terungkap sebelumnya.

Perusahaan didorong menunjukkan kinerja dan kualitas yang baik serta adanya kepentingan tertentu membuat persaingan menjadi tinggi. Sehingga manajer bisa melakukan tindakan yang dibenarkan atau tidak benar dalam mewujudnya tujuannya. Investor dan pihak luar yang berkepentingan harus memperhatikan setiap 
informasi yang ada pada laporan keuangan. Informasi dalam laporan keuangan yang baik dari manajemen adalah informasi yang memperlihatkan keadaaan sebenarnya bukan laporan keuangan yang diubah dan di manipulatif.

Beberapa faktor yang berpengaruh terhadap manajemen laba antara lain adalah free cash flow, financial distress dan investment opportunity set. Manajemen laba dapat didorong oleh free cash flow yang memperlihatkan sisa kas setelah dikurangi biaya operasi dan belanja modal dalam bentuk dividen yang diberikan ke investor. Financial distress adalah keadaan perusahaan yang buruk yang diduga juga dapat mendorong manajemen mengubah laporan keuangan dengan cara menaikkan nilai laba. Selain itu investment opportunity set yang memperlihatkan kesempatan investasi dan bertumbuh dapat diduga juga menjadi alasan untuk melakukan manajemen laba.

Tujuan penelitian pada penelitian ini adalah untuk mengetahui apakah free cash flow, financial distress, dan investment opportunity set dapat mempengaruhi manajemen laba.

\section{Pengembangan Hipotesis}

\section{Pengaruh Free Cash Flow Terhadap Manajemen Laba}

Tingginya free cash flow perusahaan memberikan peluang bagi manajemen untuk melakukan manajemen laba. Hal ini terjadi karena adanya masalah keangenan (Hastuti et al. (2018:1135). Teori agensi menyatakan bahwa konflik kepentingan terjadi karena perbedaan kepentingan antara prinsipal dengan agen. Dimana prinsipal ingin meningkatkan kesejahteraannya dengan dibagikan free cash flow yang ada dalam bentuk dividen. Bagi manajer pembagian dividen dianggap dapat mengurangi sumber daya kekuasaannya untuk melakukan investasi kembali.

Sesuai dengan teori agensi berkaitan dengan adanya perbedaan kepentingan (conflict of interest), prinsipal tentu menginginkan kesejahteraannya meningkat. Sehingga, mereka ingin agar free cash flow yang ada dibagikan dalam bentuk dividen.
Sedangkan, manajer menganggap pembagian dividen itu akan mengurangi sumber daya yang berada dalam kekuasaannya yang seharusnya dapat digunakan untuk diinvestasikan kembali.

Free cash flow adalah sisa kas pendanaan proyek yang dapat memberikan NPV (net present value) bernilai positif Jensen (1986:2). Manajer terdorong untuk melakukan reinvestment dengan tujuan untuk memperbesar perusahaan, yang pada akhirnya invetasi tersebut tidak memberikan hasil yang menguntungkan atau NPV yang diperoleh negatif. Ini bisa terjadi jika pengawasan dari prisipal rendah. Investasi yang berlebihan dapat mengakibatkan laba turun walaupun ukuran perusahaan menjadi besar. Penggunaan dari free cash flow yang tidak efisien diatasi dengan cara melakukan manajemen laba yaitu menutupi kerugian dengan meningkatkan laba. Laba yang meningkat ini, manajer berharap ada insentif dan bonus yang diterima. Tindakan manajer yang melakukan manajemen laba dengan dasar untuk mendapatkan bonus dinamakan bonus plan hypothesis dalam teori akuntansi positif. Hasil penelitian telah menunjukkan hasil bahwa manajemen laba dapat dipengaruhi oleh free cash flow dengan nilai signifikan yang positif dari penelitian Hastuti et al. (2018), Kodriyah dan Fitri (2017), Nouri dan Gilaninia (2017), dan Bukit dan Nasution (2015), ,

$\mathrm{Ha}_{1}$ : Free cash flow berpengaruh positif terhadap manajemen laba.

\section{Pengaruh Financial Distress Terhadap Manajemen Laba}

Financial distress adalah suatu keadaan dimana perusahaan sedang dalam keadaan kesulitan keuangan dan berada diambang kebangkrutan. Penyebab utama terjadinya financial distress adalah kinerja yang menurun cenderung buruk dari perusahaan (Ghazali et al., 2015:195). Teori agensi menjelaskan bahwa perusahaan yang menghadapi keadaan financial distress menjadi bermasalah disebabkan oleh adanya informasi yang asimetri dan juga adanya perbedaan kepentingan. Kondisi ini merupakan peluang untuk manajer mengambil tindakan opportunis dalam 
rangka memperbaiki kinerja yang rendah dengan manajemen laba (Sari dan Meiranto, 2017:4).

Perusahaan dalam kondisi financial distress memperlihatkan bahwa manajer dalam pengelolaan perusahaan tidak dilakukan secara baik. Sehingga prinsipal cenderung untuk melakukan penggantian manajer (Noviantari dan Ratnadi, 2015:648). Upaya yang dilakukan manajer dalam menghadapi kondisi financial distress ini, sesuai dengan penjelasan dari teori akuntansi positif, maka manajer dalam rangka mendapatkan tujuaannya akan menggunakan prosedur dan metode akuntansi untuk bisa menaikkan laba. Hasil penelitian memperlihatkan bahwa manajemen laba dapat dipengaruhi financial distress dengan nilai signifikan positif dari penelitian yang dilakukan Chairunesia, et al. (2018), Paramita et al. (2017), dan Saputri dan Achmad (2017).

$\mathrm{Ha}_{2}$ : Financial distress berpengaruh positif terhadap manajemen laba.

\section{Pengaruh Investment Opportunity Set Terhadap Manajemen Laba}

Investment opportunity set (IOS) dari suatu perusahaan memperlihatkan proyeksi pertumbuhan perusahaan kedepannya. Nilai investment opportunity set (IOS) yang diharapkan adalah yang tinggi karena akan mencerminkan pertumbungan perusahaan yang tinggi juga. Tapi nilai yang tinggi dari investment opportunity set (IOS) mengandung banyak informasi yang asimetri yang terjadi antara prinsipal dengan manajer disebabkan susahnya melihat opsi pertumbuhan yang disajikan. Informasi dalam perusahaan yang sulit untuk diketahui oleh pihak eksternal antara lain adalah investment opportunity set (IOS) (Juanna, 2015:21).

Informasi yang diberikan perusahaan ke pihak luar adalah dengan memperlihatkan laba pada laporan keuangan. Manajemen laba dilakukan dengan cara menaikkan laba, sehingga dapat memperlihatkan investment opportunity set (IOS) yang tinggi dan ini dapat menunjukkan memproyeksi pertumbuhan perusahaan yang baik untuk kedepannya dan akan menguntungkan investor. Dari hasil penelitian membuktikan bahwa manajemen laba dapat dipengaruhi investment opportunity set (IOS) dengan nilai signikan positif yang diteliti oleh Nurlis (2016) dan Agustina et al. (2015).

$\mathrm{Ha}_{3}: \quad$ Investment opportunity set berpengaruh positif terhadap manajemen laba.

Gambar 1. Kerangka Pemikiran

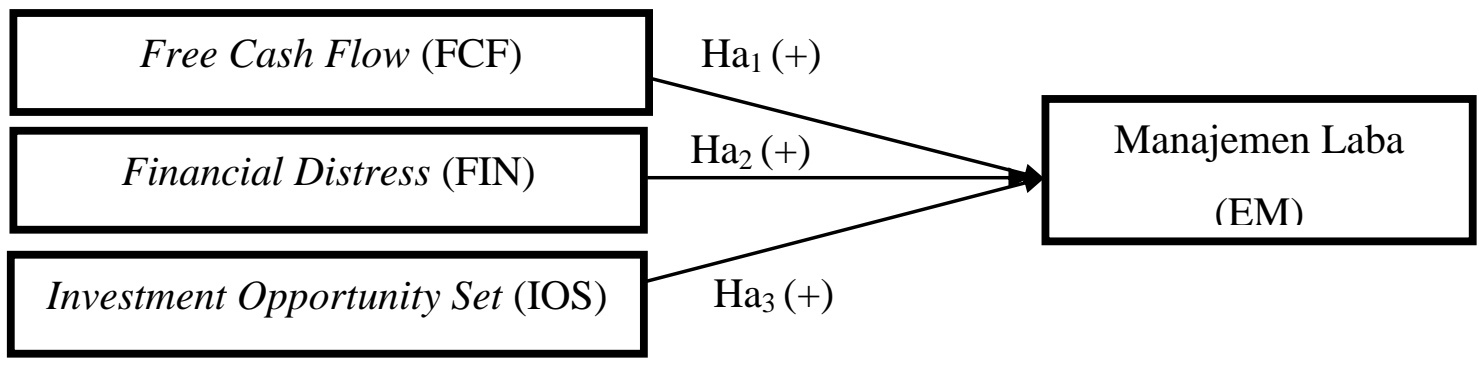

\section{Metode Penelitian}

Objek yang digunakan dalam penelitian ini yaitu perusahaan infrastruktur, utilitas, dan transportasi yang terdaftar di Bursa Efek Indonesia periode 2014-2018 yang laporan keuangannya didapat dari www.idx.co.id. Sektor infrastruktur, utilitas dan trnasportasi dijadikan objek penelitian karena ada kasus manajemen laba pada tahun 2018

Pemilihan sampel dilakukan secara purposive sampling method dengan kriteriakriteria yang ditentukan dalam pengambilan sampel penelitian ini yaitu: (1) Perusahaan sektor infrastruktur, utilitas, dan transportasi yang terdaftar di BEI selama periode 2014-2018, (2) Perusahaan yang 
tidak pernah delisting dari BEI selama periode 2014-2018, (3) Perusahaan yang menerbitkan laporan keuangan dengan periode yang berakhir pada tanggal 31 Desember, (4) Perusahaan menyajikan laporan keuangan dalam satuan mata uang rupiah, (5) Perusahaan yang tidak mencatatkan kerugian, (6) Perusahaan menerbitkan laporan keuangan tahunan secara lengkap serta memiliki data yang lengkap mengenai variabel yang diteliti. Jumlah sampel yang digunakan dalam penelitian ini adalah sebanyak 11 perusahaan dengan periode pengamatan selama lima tahun sebesar 55 sampel.

\section{Variabel Penelitian}

\section{Manajemen Laba}

Variabel dependen dalam penelitian ini adalah manajemen laba. Manajemen laba sebagai variabel dependen diproksikan dengan discretionary accruals. Discretionary accruals (DA) merupakan tingkat akrual yang tidaknormal yang berasal dari kebijakan manajemen untuk melakukan rekayasa terhadap laba sesuai keinginan mereka. Discretionary accruals dihitung dengan menggunakan model pengukuran Modified Jones Model karena model ini dianggap sebagai model yang paling baik dalam mendeteksi manajemen laba dan memberikan hasil yang kuat (Dechow, Sloan, \& Sweeney, 1995). Rumus yang digunakan untuk menghitung manajemen laba dengan metode discretionary accruals Modified Jones Model (Dechow et al., 1995) adalah sebagai berikut:

a. Menentukan nilai Total Accruals (TA)

$\mathrm{TA}_{\mathrm{t}}=\mathrm{NI}_{\mathrm{t}}-\mathrm{CFO}_{\mathrm{t}}$

b. Total Accruals yang diestimasi dengan persamaan regresi OLS (Ordinary Least Square)

$\frac{\mathrm{TA}_{\mathrm{t}}}{\mathrm{A}_{\mathrm{t}-1}}=\beta_{1} \frac{1}{\mathrm{~A}_{\mathrm{t}-1}}+\beta_{2} \frac{\Delta \mathrm{REV}_{\mathrm{t}}-\Delta \mathrm{REC}_{\mathrm{t}}}{\mathrm{A}_{\mathrm{t}-1}}+\beta_{3} \frac{\mathrm{PPE}_{\mathrm{t}}}{\mathrm{A}_{\mathrm{t}-1}}+\varepsilon$

c. Menghitung nilai Non-discretionary Accruals (NDA)

$\mathrm{NDA}_{\mathrm{t}}=\beta_{1} \frac{1}{\mathrm{~A}_{\mathrm{t}-1}}+\beta_{2} \frac{\Delta \mathrm{REV}_{\mathrm{t}}-\Delta \mathrm{REC}_{\mathrm{t}}}{\mathrm{A}_{\mathrm{t}-1}}+\beta_{3} \frac{\mathrm{PPE}_{\mathrm{t}}}{\mathrm{A}_{\mathrm{t}-1}}$ d. Menghitung nilai Discretionary Accruals (DA)

$$
\mathrm{DA}_{\mathrm{t}}=\frac{\mathrm{TA}_{\mathrm{t}}}{\mathrm{A}_{\mathrm{t}-1}}-\mathrm{NDA}_{\mathrm{t}}
$$

Keterangan:

$\mathrm{TA}_{\mathrm{t}}=$ Total accruals pada periode $\mathrm{t}$

$\mathrm{NDA}_{\mathrm{t}}=$ Non-discretionary accruals perusahaan pada periode $\mathrm{t}$

DA $_{\mathrm{t}}=$ Discretionary accruals perusahaan pada periode $\mathrm{t}$

$\mathrm{NI}_{\mathrm{t}} \quad=$ Laba bersih perusahaan pada periode $\mathrm{t}$

$\mathrm{CFO}_{\mathrm{t}}=$ Arus kas operasi perusahaan pada periode $\mathrm{t}$

$\mathrm{A}_{\mathrm{t}-1}=$ Total aset perusahaan pada periode $\mathrm{t}$

$\Delta \mathrm{REV}_{\mathrm{t}}=$ Pendapatan perusahaan pada periode $\mathrm{t}$ dikurangi pendapatan perusahaan pada periode $\mathrm{t}-1$

$\Delta \mathrm{REC}_{\mathrm{t}}=$ Piutang usaha perusahaan pada periode $t$ dikurangi piutang usaha perusahaan pada periode $\mathrm{t}-1$

$\mathrm{PPE}_{\mathrm{t}} \quad=$ Property, plan, and equipment perusahaan pada periode $\mathrm{t}$

$\varepsilon \quad=$ Error

\section{Free Cash Flow}

Free cash flow adalah sisa laba yang ada yang akan dibagikan untuk investor dan kreditor setelah dikurangi biaya operasional, investasi aset tetap dan juga modal kerja untuk berjalannya usaha perusahaan. Variabel ini dihitung menggunakan rumus Brigham \& Houston (2016), yaitu:

Free Cash Flow = NOPAT - Investasi

Bersih pada Modal Operasi

Keterangan:

NOPAT $=$ Laba operasi bersih setelah pajak Investasi Bersih Pada Modal Operasi = Total modal operasi $i_{t}$ - total modal operasi $i_{t-1}$ Total Modal Operasi $=$ Modal kerja operasi bersih + aset tetap bersih

Modal Kerja Operasi Bersih = Aset lancar kewajiban lancar

Mengacu pada penelitian Agustia (2013), free cash flow dalam penelitian ini diukur menggunakan skala rasio, dimana 
nilai free cash flow dibagi dengan total aset pada periode yang sama dengan tujuan agar lebih comparable bagi perusahaanperusahaan yang dijadikan sampel.

\section{Financial Distress}

Kondisi keuangan perusahaan yang buruk dan terus turun akan mengancam keberadaan usaha perusahaan atau menuju bangkrut dinamakan Financial distress. Pada penelitian ini, financial distress diukur dengan Model Altman Modifikasi Z-Score yang dapat diterapkan pada semua perusahaan, yaitu perusahaan manufaktur dan non-manufaktur. Model ini dianggap sebagai prediktor terbaik untuk mengukur financial distress dibandingkan dengan model pengukuran lainnya dengan tingkat ketepatan prediksi sebesar 95\%. Berikut persamaan Z-Score menurut Model Altman Modifikasi (Altman, 2000):

$Z=6,56 X_{1}+3,26 X_{2}+6,72 X_{3}+1,05 X_{4}$

Keterangan:

$\mathrm{X}_{1}=$ working capital $/$ total asset

$\mathrm{X}_{2}=$ retained earnings / total asset

$\mathrm{X}_{3}=$ earning before interest and taxes / total asset

$\mathrm{X}_{4}=$ book value of equity / book value of total debt

Klasifikasi financial distress:

Nilai $\mathrm{Z}<1,1=$ dalam kondisi financial distress

Nilai $1,1<Z<2,6=$ grey area

Nilai $Z>2,6=$ tidak dalam financial distress

\section{Investment Opportunity Set}

Investment opportunity set menggambarkan tentang luasnya kesempatan pertumbuhan atau peluang investasi bagi suatu perusahaan. Pada penelitian ini, investment opportunity set diukur menggunakan rasio market value to book value of asset(MVBVA) yang termasuk dalam proksi berbasis harga karena proksi ini merupakan proksi yang paling banyak digunakan dalam mengukur investment opportunity set sebuah perusahaan. Selain itu, proksi ini termasuk salah satu proksi yang memiliki konsistensi dan korelasi sebagai proksi pertumbuhan yang paling valid. Proksi berbasis harga didasarkan pada asumsi bahwa perusahaan yang tumbuh akan memiliki nilai pasar yang relatif lebih tinggi terhadap aset yang ada karena prospek pertumbuhan setidaknya akan tercermin dalam harga saham. Rasio MVBVA ini mencerminkan pertumbuhan perusahaan yang dinyatakan dalam harga pasar (Kallapur dan Trombley dalam Utama \& Sulistika, 2015):

MVBVA=

$\underline{[(\text { Total Aset-Total Ekuitas })+(\Sigma \text { Lembar Saham Beredar x Closing Price })]}$ Total Aset

\section{Hasil Dan Pembahasan Hasil Penelitian}

\section{Statistik Deskriptif}

Dari hasil uji statistik deskriptif peneliti bertujuan untuk melihat gambaran mengenai data dari nilai mean, nilai minimum, nilai maksimum, dan standar deviasi dari setiap variabel yang diteliti. Dapat disimpulkan apabila mean lebih besar daripada standard deviasi maka data memiliki nilai yang hampir sama (homogen) atau berada di sekitar nilai ratarata seperti yang terlihat pada tabel 1

\section{Uji Kesamaan Koefisien}

Uji kesamaan koefisien dilakukan untuk melihat apakah pooling data (penggabungan antara data cross sectional dan data time series) dapat dilakukan. Dari hasil uji pooling yang terdapat pada Tabel 2 menunjukkan bahwa hasil dari seluruh variabel dummy tahun dan interaksinya memiliki nilai signifikan di atas 0,05 . Hasil ini menunjukkan bahwa pooling data dapat dilakukan.

\section{Uji Asumsi Klasik}

Uji normalitas dilakukan untuk melihat apakah model regresi yang 
digunakan dalam penelitian ini memiliki distribusi yang normal. Hasil uji normalitas yang terdapat pada Tabel 3 menunjukkan hasil Asymp. Sig. (2tailed) sebesar 0,001 lebih rendah dari 0,05 yang berarti data tidak berdistribusi normal. Namun menurut Anderson et al. (2018:321) berdasarkan central limit theorem untuk jumlah sampel $\geq 30$, maka data akan cenderung menyebar menurut sebaran normal atau data berdistribusi normal.

Uji multikolinearitas digunakan untuk menguji apakah model regresi ditemukan adanya korelasi antar variabel independen. Hasil pengujian yang terdapat pada Tabel 3 menunjukkan bahwa setiap variabel memiliki nilai tolerance $>0,10$ dan < 10. Maka dapat disimpulkan tidak terdapat multikolinearitas antara variabel independen dalam model regresi.

Uji autokorelasi bertujuan untuk menguji apakah dalam suatu model regresi linear terdapat korelasi antara kesalahan pengganggu pada periode $\mathrm{t}$ dengan kesalahan pengganggu pada periode t-1 (sebelumnya). Pengujian dilakukan dengan uji Durbin Watson (DW). Hasil pengujian yang terdapat pada Tabel 3 menunjukkan nilai DW 2,284 yang terletak di antara dU $(1,6815)$ dan 4-dU $(2,3185)$. Sehingga, dapat disimpulkan tidak terjadi autokorelasi pada model regresi ini.

Uji heteroskedastisitas bertujuan untuk menguji apakah dalam model regresi terjadi ketidaksamaan variance dari residual satu pengamatan ke pengamatan yang lain. Pengujian dilakukan dengan uji Park. Hasil pengujian yang terdapat pada Tabel 3 menunjukkan bahwa nilai signifikansi setiap variabel lebih besar dari 0,05 . Maka, dapat disimpulkan pada model regresi tidak terjadi heteroskedastisitas.

\section{Regresi Linear Berganda}

Hasil penelitian yang telah dilakukan dengan menggunakan program SPSS 22 menunjukkan persamaan regresi linear berganda sebagai berikut:

$\mathrm{EM}=0,021+0,026 \mathrm{FCF}-0,001 \mathrm{FIN}$ $+0,009$ IOS

Hasil analisis regresi berganda pada model persamaan di atas menghasilkan nilai konstanta 0,021 yang berarti apabila FCF, FIN, dan IOS bernilai 0, maka manajemen laba bernilai 0,021 . Koefisien regresi untuk FCF adalah 0,026, artinya setiap kenaikan satu persen FCF, maka akan mengakibatkan peningkatan manajemen laba sebesar 0,026 dengan asumsi variabel independen lainnya bernilai tetap. Koefisien regresi untuk FIN adalah 0,001 , artinya setiap kenaikan satu persen nilai $\mathrm{z}$-score, maka akan mengakibatkan penurunan manajemen laba sebesar 0,001 dengan asumsi variabel independen lainnya bernilai tetap. Koefisien regresi untuk IOS adalah 0,009, artinya setiap kenaikan satu persen IOS, maka akan mengakibatkan peningkatan nilai manajemen laba sebesar 0,009 dengan asumsi variable independen lainnya bernilai tetap.

Uji statistik $\mathrm{F}$ digunakan untuk menguji apakah seluruh variabel independen yang dimasukkan dalam model secara bersama-sama mempunyai pengaruh yang signifikan terhadap variabel dependen atau apakah model regresi layak dipakai atau tidak. Berdasarkan hasil uji $\mathrm{F}$ diperoleh nilai signifikansi yang lebih kecil dari 0,05 yaitu 0,035. Maka, dapat disimpulkan bahwa free cash flow, financial distress, dan investment opportunity set secara bersama-sama atau secara simultan mempunyai pengaruh terhadap manajemen laba. 
Hasil uji statistik t yang diperoleh menunjukkan bahwa free cash flow dan investment opportunity set dapat mempengaruhi manajemen laba secara signifikan positif, tapi manajemen laba tidak bisa dipengaruhi financial distress

Hasil uji koefisien determinasi $\left(\mathrm{R}^{2}\right)$ menunjukkan bahwa proporsi pengaruh variabel independen yaitu free cash flow, financial distress, dan investment opportunity set terhadap variabel manajemen laba sebesar $15,4 \%$.

\section{Pembahasan}

Berdasarkan hasil penelitian pada Tabel 4, variabel free cash flow memiliki nilai signifikansi sebesar $0,036(0,072 / 2)$. Hasil pengujian tersebut memperoleh nilai lebih rendah dari tingkat signifikansi 5\% dan koefisien regresi yang diperoleh menunjukkan arah yang positif yaitu 0,026. Hal ini menunjukkan bahwa free cash flow terbukti berpengaruh signifikan positif terhadap manajemen laba, sehingga hipotesis pertama $\left(\mathrm{Ha}_{1}\right)$ diterima. Hasil penelitian ini sejalan dengan Hastuti et al. (2018), Nouri dan Gilaninia (2017), dan juga Kodriyah dan Fitri (2017) yang menyatakan bahwa manajemen laba dipengaruhi free cash flow dengan nilai signifikan positif. Free cash flow yang dimiliki perusahaan besar, semakin besar pula indikasi manajemen dalam melakukan manajemen laba. Hal ini berkaitan dengan teori agensi menurut Jensen dan Meckling (1976:308) dan Bosse \& Phillips (2016:278), yaitu adanya konflik kepentingan antara agent dan principal. Principal menginginkan agar free cash flow tersebut dibagikan dalam bentuk dividen untuk memaksimalkan kesejahteraannya, sedangkan manajer lebih memilih untuk menggunakan free cash flow tersebut untuk diinvestasikan kembali, walaupun hasil akhirnya investasi yang dilakukan tidak memberikan laba bagi perusahaan. Walaupun tindakan ini dapat memperbesar ukuran perusahaan, tetapi perusahaan mengalami kerugian atau penurunan laba akibat penyalahgunaan free cash flow yang dilakukan oleh manajer ini. Hal inilah yang kemudian mendorong manajer melakukan manajemen laba untuk menutupi kerugian akibat ketidakefisienan dalam penggunaan free cash flow. Selain itu, sesuai teori akuntanti positif yang dikemukakan Watts dan Zimmerman (1986:208-216,235), manajer melakukan manajemen laba dalam rangka mendapatkan insentif atau bonus (bonus plan hypothesis) karena investasi yang dilakukannya dalam rangka memperbesar ukuran perusahaan ternyata berhasil dan dapat memberi keuntungan bagi perusahaan, meskipun pada kenyataannya keuntungan yang dicatatkan hanya manipulasi yang dilakukan manajer. Berdasarkan hasil penelitian pada Tabel 4, variabel financial distress memiliki nilai signifikansi sebesar 0,2415 (0,483/2). Hasil pengujian tersebut memperoleh nilai lebih tinggi dari tingkat signifikansi $5 \%$ yang berarti financial distress tidak cukup bukti memiliki pengaruh yang signifikan terhadap manajemen laba, sehingga tidak hipotesis kedua (Ha2) ditolak. Hasil penelitian ini tidak sejalan dengan Gupta dan Suartana (2018) dan Paramita et al. (2017), mengatakan bahwa manajemen laba dapat dipengaruhi secara positif oleh financial distress, serta tidak sejalan dengan penelitian Ghazali et al. (2015) yang menyatakan bahwa financial distress berpengaruh signifikan negatif terhadap manajemen laba. Akan tetapi, sejalan dengan penelitian Yolanda et al. (2019) dan Fathoni et al. (2014), menyatakan bahwa manajemen laba tidak dapat dipengaruhi oleh financial distress. Hasil penelitian menunjukkan Altman modifikasi z-score sebagai proksi dari financial distress tidak berpengaruh signifikan terhadap manajemen laba. Hal ini memberikan pengertian bahwa perusahaan yang mengalami kondisi financial distress tidak akan selalu mendorong dilakukannya manajemen laba. Perusahaan yang mengalami kesulitan keuangan menganggap bahwa tindakan manajemen laba justru dapat merugikan perusahaan lebih besar kedepannya, sehingga mereka akan lebih memilih melaporkan laba yang sesunguhnya sebagai tanda baik kepada pihak luar yang akan dapat mengurangi 
informasi yang asimetri (Moratis, 2018:3) dibanding melakukan manajemen laba. Apabila perusahaan terdeteksi melakukan manajemen laba, maka akan kehilangan kepercayaan dari para pemangku kepentingan seperti pemegang saham. Tentunya investor akan lebih mempercayai perusahaan yang reputasinya baik, tidak hanya dari segi laba yang diperoleh, tapi juga dari good record yang diperoleh perusahaan, seperti tidak pernah terindikasi melakukan kecurangan laporan keuangan. Bila perusahaan mengalami financial distress, para investor mungkin akan berpikir dua kali untuk menanamkan modalnya atau melanjutkan penanaman modalnya pada perusahaan itu. Akan tetapi, ada kemungkinan investor dapat melanjutkan penanaman modalnya dengan mempertimbangkan faktor-faktor lain dari perusahaan yang dinilai dapat menguntungkan bagi investor atau investor berharap dengan citra baik yang dimiliki perusahaan dapat memulihkan kondisi keuangan perusahaan ke depannya karena dalam bisnis tidak selalu berjalan mulus. Sedangkan, apabila perusahaan sudah mengalami financial distress dan terindikasi melakukan tindakan kecurangan yaitu manajemen laba, akan lebih besar kemungkinan investor tidak akan menanamkan modalnya pada perusahaan itu dan hal ini membuat perusahaan semakin sulit memecahkan kesulitan kondisi keuangannya karena rendahnya modal yang dimiliki.

Berdasarkan hasil penelitian pada Tabel 4, variabel investment opportunity set memiliki nilai signifikansi sebesar 0,025 $(0,050 / 2)$. Hasil pengujian tersebut memperoleh nilai lebih rendah dari tingkat signifikansi 5\% dan koefisien regresi yang diperoleh menunjukkan arah yang positif yaitu 0,009. Hal ini menunjukkan bahwa investment opportunity set terbukti berpengaruh signifikan positif terhadap manajemen laba, sehingga hipotesis ketiga (Ha3) diterima. Hasil penelitian ini sejalan dengan penelitian Agustina et al. (2015) dan Nurlis (2016) yang menyatakan bahwa investment opportunity set berpengaruh positif dan signifikan terhadap manajemen laba. Hasil pengujian menunjukkan semakin besar investment opportunity set yang dimiliki perusahaan, maka semakin besar manajemen laba yang dilakukan, dimana investment opportunity set ini memperlihatkan besarnya peluang dan kesempatan investasi perusahaan. Investment opportunity set adalah informasi internal yang dimiliki manajer dan susah diketahui pihak diluar perusahaan (Juanna, 2015:21). Berkenaan dengan teori agensi yaitu terdapatnya asimetri informasi antara manajer sebagai agent dan pemegang saham sebagai principal dimana manajer tentunya memiliki lebih menyeluruh tentang keadaan keberlangsungan perusahaan ke depannya karena manajer yang turun langsung dalam segala pengoperasian kegiatan perusahaan (Jensen dan Meckling, 1976:308). Upaya manajer menyampaikan informasi internal ke pihak diluar perusahaan dan pemegang saham melalui laba yang dilaporkan yaitu dengan melakukan manajemen laba untuk memberikan informasi internal tentang prospek perkembangan yang dimiliki perusahaan dimana depan. Hal ini berkaitan dengan teori sinyal yaitu tentang pentingnya informasi yang disampaikan oleh perusahaan terhadap keputusan investasi oleh pihak eksternal perusahaan, dimana informasi tersebut akan dianalisis sebagai sinyal positif (good news) atau sinyal negatif (bad news) (Suhartono 2015:191). Sehingga, perusahaan yang memiliki investment opportunity set tinggi akan melakukan manajemen laba untuk memberikan sinyal positif bagi investor bahwa perusahaan memiliki prospek pertumbuhan yang baik dan menguntungkan di masa depan. Dari 3 variabel yang diteliti terdapat variabel financial distress yang tidak menunjukkan pengaruhnya terhadap manajemen laba. Manajer yang menghadapi kondisi rugi cenderung untuk mentupi kerugiannya. Akan tetapi, dari hasil penelitian manajemen cenderung memilih menyediakan data keadaan sebenarnya terhadap pemegang saham (shareholders).

\section{Simpulan}

Berdasarkan hasil penelitian dapat diambil kesimpulan penelitian ini 
menunjukkan bahwa terdapat cukup bukti bahwa free cash flow berpengaruh positif dan signifikan terhadap manajemen laba, tidak terdapat cukup bukti bahwa financial distress memiliki pengaruh signifikan terhadap manajemen laba, dan terdapat cukup bukti bahwa investment opportunity set berpengaruh positif dan signifikan terhadap manajemen laba.

Berdasarkan hasil analisis dan kesimpulan yang telah diuraikan, dapat diberikan saran bagi perusahaan agar melakukan pengawasan terhadap kinerja manajer sehingga manajer bekerja sesuai dengan kepentingan principal dan perusahaan. Bagi para investor dan kreditor sebaiknya dalam menilai laporan keuangan perusahaan tidak hanya berfokus pada informasi laba saja, karena dapat saja laba yang dilaporkan tidak mencerminkan keadaan perusahaan yang sesungguhnya. Selain itu, sebaiknya investor dan kreditor dapat memahami berbagai macam pola manajemen laba dan dapat menganalisis manajemen laba dari nilai free cash flow dan investment opportunity set yang dimiliki perusahaan pada laporan keuangan, karena penelitian ini telah membuktikan bahwa perusahaan dengan free cash flow dan investment opportunity set yang tinggi cenderung melakukan manajemen laba. Bagi regulator, sebaiknya melihat kembali metode akuntansi yang memberi celah bagi manajemen untuk melakukan manajemen laba. Keterbatasan pada penelitian ini adalah hanya mencakup sektor infrastruktur, utilitas, dan transportasi. Bagi peneliti selanjutnya yang ingin melakukan penelitian sejenis, disarankan untuk memperluas sampel penelitian dengan tidak hanya pada sektor perusahaan infrastruktur, utilitas, dan transportasi saja. Selain itu, dapat menambah atau memilih variabel independen yang lain agar sampel yang digunakan dapat lebih banyak dengan harapan dapat mencerminkan hasil penelitian yang lebih general. Berdasarkan hasil penelitian menunjukkan bahwa financial distress dengan proksi Altman modifikasi z-score tidak berpengaruh terhadap manajemen laba, maka peneliti selanjutnya dapat meneliti pengaruh financial distress terhadap manajemen laba menggunakan proksi lain seperti model Springate atau Zmijewski.

\section{Daftar Pustaka}

Agustia, Dian. (2013). Pengaruh Faktor Good Corporate Governance, Free Cash Flow, dan Leverage Terhadap Manajemen Laba. Jurnal Akuntansi Dan Keuangan, Vol. 15, No. 1,p. 2742.

Agustina, Islahuddin, \& Muhammad Arfan (2015), Pengaruh Set Peluang Investasi dan Financial Leverage Terhadap Return Saham yang Dimediasi Oleh Manajemen Laba (Studi Pada Perusahaan Manufaktur Periode 2010-2013 yang Terdaftar di Bursa Efek Indonesia, Jurnal Magister Akuntansi, Vol. 4, No. 3, p.27-38.

Altman, Edward I. (2000), Predicting Financial Distress of Companies: Revisiting The Z-Score and Zeta ( Models, New York University, Stern School of Business.

Anderson, David R., Dennis J. Sweeney, Thomas A. Williams, Jeffrey D. Camm, \& James J. Cochran (2018), Essentials of Statistics for Business and Economics, Edisi 8, Boston: Cengage Learning.

Assih, Prihat (2006), The Effect Of Investment Opportunity Set On The Association Between Incentives And Earnings Management Level, The International Journal of Accounting and Business Society, Vol. 14, No. 1, p.1-15.

Bosse, Douglas A., dan Robert A. Phillips (2016), Agency Theory and Bounded Self-Interest, Academy of Management Review, Vol. 41, No. 2, p.276-297.

Brigham, Eugene F. dan Joel F. Houston (2016), Fundamentals of Financial Management, 14th Edition, Boston: Cengage Learning.

Bukit, Rina $\mathrm{Br}$ dan Fahmi N. Nasution (2015), Employee Diff, Free Cash Flow, Corporate Governance and Earnings Management, Procedia - 
Social and Behavioral Sciences, Vol. 211, p.585-594.

Chairunesia, Wieta, Putri Renalita Sutra, \& Sely Megawati Wahyudi (2018), Pengaruh Good Corporate Governance dan Financial Distress Terhadap Manajemen Laba Pada Perusahaan Indonesia yang Masuk ke Dalam ASEAN Corporate Governance Scorecard, Profita: Komunikasi Ilmiah Akuntansi Dan Perpajakan, Vol. 11, No. 2, p.232250.

CNN Indonesia 2019, Membedah Keanehan Laporan Keuangan Garuda Indonesia 2018, diakses 15 Oktober 2019 , https://www.cnnindonesia.com/ekon omi/20190424204726-92-

389396/membedah-keanehanlaporan-keuangan-garuda-indonesia2018

Dechow, Patricia M., Richard G. Sloan, \& Amy P. Sweeney (1995), Detecting Earnings Management, The Accounting Review, Vol. 70, No. 2, p.193-225.

Fathoni, Ahmad Fauzan, Haryetti, Errin Yani Wijaya, \& Muchsin (2014), The Effect of Good Corporate Governance Mechanism, Financial Distress on Earning Management Behavior: Empirical Study in Property and Infrastructure Industry in Indonesian Stock Exchanges, Jurnal Ekonomi, Vol. 22, No. 1, p.116.

Ghazali, Aziatul Waznah, Nur Aima Shafie, \& Zuraidah Mohd Sanusi (2015). Earnings Management: An Analysis of Opportunistic Behaviour, Monitoring Mechanism and Financial Distress. Procedia Economics and Finance, Vol. 28, p.190-201.

Gul, Ferdinand A., Sidney Leung, \& Bin Srinidhi (2000), The Effect of Investment Opportunity Set and Debt Level on Earnings-Returns Relationship and the Pricing of Discretionary Accruals, Social Science Research Network Electronic
Paper Collection, City University of Hongkong, July.

Gupta, Ayu Taradyan dan I Wayan Suartana (2018), Pengaruh Financial Distress dan Kualitas Corporate Governance Pada Manajemen Laba, E-Jurnal Akuntansi Universitas Udayana, Vol. 23, No. 2, p.14951520.

Hastuti, Cut Sri Firman, Muhammad Arfan, \& Yossi Diantimala (2018), The Influence of Free Cash Flow and Operating Cash Flow on Earnings Management at Manufacturing Firms Listed in the Indonesian Stock Exchange, International Journal of Academic Research in Business \& Social Sciences, Vol. 8, No. 9, p.1133-1146.

Jensen, Michael C. (1986), Agency Costs of Free Cash Flow, Corporate Finance, and Takeovers. American Economic Review, Vol. 76, No. 2, p.323-329.

Jensen, Michael C. dan William $\mathrm{H}$. Meckling (1976), Theory of The Firm: Managerial Behavior, Agency Costs and Ownership Structure, Journal of Financial Economics, Vol. 3, p.305-360.

Juanna (2015), Pengaruh Set Kesempatan Investasi Terhadap Manajemen Laba dan Dampaknya Terhadap Return Saham Pada Perusahaan Manufaktur yang Terdaftar di Bursa Efek Indonesia Tahun 2007-2009, Jurnal Telaah Dan Riset Akuntansi, Vol. 8, No. 1, p.19-34.

Kodriyah dan Anisah Fitri (2017), Pengaruh Free Cash Flow dan Leverage Terhadap Manajemen Laba Pada Perusahaan Manufaktur di BEI, Jurnal Akuntansi, Vol. 3, No. 2, p.64-76.

Moratis, Lars (2018). Signalling Responsibility? Applying Signalling Theory to the ISO 26000 Standard for Social Responsibility, Sustainability, Vol. 10, p.1-20.

Nouri, Saeid dan Behnam Gilaninia (2017), The Effect of Surplus Free Cash Flow and Audit Quality on Earnings Management, International Journal of 
Economics and Financial Issues, Vol. 7, No. 3, p.270-275.

Noviantari, Ni Wayan dan Ni Made Dwi Ratnadi (2015), Pengaruh Financial Distress, Ukuran Perusahaan, dan Leverage Pada Konservatisme Akuntansi, E-Jurnal Akuntansi Universitas Udayana, Vol. 11, No. 3, p.646-660.

Okezone Finance 2017, Laporan Keuangan Bermasalah, BEI Delisting Saham Inovisi Infracom, diakses 15 Oktober 2019,

https://economy.okezone.com/read/2 017/09/27/2 78/1783909/laporankeuangan-bermasalah-bei-delistingsaham-inovisi-infracom

Nurlis (2016), The Effect of Mechanism of Good Corporate Governance and Investment Opportunity Set on the Earning Management: Study On Property and Real Estate Companies Are Listed In Indonesia Stock Exchange, European Journal of Business and Management, Vol. 8, No. 2, p.173-182.

Paramita, Ni Nyoman Erni Yanuar, Edy Sujana, \& Nyoman Trisna Herawati (2017), Pengaruh Financial Distress, Risiko Litigasi, dan Pengungkapan Corporate Social Responsibility Terhadap Manajemen Laba, EJournal Akuntansi S1 Universitas Pendidikan Ganesha, Vol. 8, No. 2.

Perwitasari, Dian (2014), Struktur Kepemilikan, Karakter Perusahaan, dan Manajemen Laba, Jurnal Akuntansi Multiparadigma, Vol. 5, No. 3, p.432-441.

Saputri, Gita Oktaviany Wanda dan Tarmizi Achmad (2017), Pengaruh Faktor Finansial dan Non Finansial Terhadap Manajemen Laba (Studi Empiris Pada Perusahaan Manufaktur yang Terdaftar di Bursa Efek Indonesia Periode 2013-2015),
Diponegoro Journal of Accounting, Vol. 6, No. 3, p.1-11.

Sari, Alamanda Rosia dan Wahyu Meiranto (2017), Pengaruh Perilaku Oportunistik, Mekanisme Pengawasan, dan Financial Distress Terhadap Manajemen Laba, Diponegoro Journal of Accounting, Vol. 6, No. 4, p.1-17.

Suhartono, Sugi (2015), Pengaruh Ukuran Perusahaan, Struktur Modal, dan Ketepatan Waktu Penyampaian Laporan Keuangan Terhadap Koefisien Respon Laba yang Dimoderasi Konservatisme Akuntansi (Studi Empiris Pada Perusahaan Manufaktur yang Terdaftar di Bursa Efek Indonesia Tahun 2010), Akuntansi Keuangan, Vol. 22, No. 2, p.189-217.

Utama, Cynthia A. dan Meiti Sulistika (2015), Determinants of Investment Opportunity Set (Degree of Internationalization and Macroeconomic Variables), Gadjah Mada International Journal of Business, Vol. 17, No. 2, p.107-124.

Watts, Ross L. dan Jerold L. Zimmerman (1986), Positive Accounting Theory, New Jersey: Prentice-Hall, Inc.

Yolanda, Mita, Kinanti Woro Hapsari, Suci Nurul Akbar, \& Vinola Herawaty (2019), Pengaruh Kepemilikan Manajerial dan Kualitas Audit Terhadap Earning Management Dengan Financial Distress Sebagai Variabel Intervening (Studi Empiris Pada Perusahaan Manufaktur Yang Terdaftar di BEI 2015-2017), Prosiding Seminar Nasional Pakar Ke 2. 
Lampiran

Tabel 1. Hasil Statistik Deskriptif

Descriptive Statistics

\begin{tabular}{|c|c|c|c|c|c|c|}
\hline & & $\mathrm{N}$ & Minimum & Maximum & Mean & Std. Deviation \\
\hline EM & & 55 & .000840 & .104800 & .033877 & .025923 \\
\hline FCF & & 55 & -.711440 & .684830 & .006378 & .234412 \\
\hline FIN & & 55 & -.227760 & 15.873550 & 3.894329 & 2.968315 \\
\hline IOS & & 55 & .537540 & 3.7985910 & 1.772810 & .812851 \\
\hline $\begin{array}{l}\text { Valid } \\
\text { (listwise) }\end{array}$ & $\mathrm{N}$ & & & & & \\
\hline
\end{tabular}

Tabel 2. Hasil Uji Kesamaan Koefisien

\begin{tabular}{|c|c|c|c|c|c|c|}
\hline \multicolumn{7}{|c|}{ Coefficients $^{\mathrm{a}}$} \\
\hline & \multirow[b]{2}{*}{ Model } & \multicolumn{2}{|c|}{ Unstandardized Coefficients } & \multirow{2}{*}{$\begin{array}{c}\text { Standardized } \\
\text { Coefficients } \\
\text { Beta }\end{array}$} & \multirow[b]{2}{*}{$\mathrm{t}$} & \multirow[b]{2}{*}{ Sig. } \\
\hline & & $\mathrm{B}$ & Std. Error & & & \\
\hline \multirow[t]{20}{*}{1} & (Constant) & .044 & .034 & & 1.267 & .214 \\
\hline & FCF & -.015 & .052 & -.132 & -.282 & .780 \\
\hline & FIN & -.003 & .003 & -.295 & -.903 & .373 \\
\hline & IOS & -.001 & .018 & -.047 & -.085 & .933 \\
\hline & D1 & -.005 & .045 & -.075 & -.106 & .916 \\
\hline & D2 & -.056 & .048 & -.868 & -1.157 & .255 \\
\hline & D3 & -.026 & .046 & -.400 & -.556 & .582 \\
\hline & D4 & -.040 & .044 & -.617 & -.897 & .376 \\
\hline & D1.FCF & .063 & .083 & .146 & .764 & .450 \\
\hline & D1.FIN & .000 & .005 & -.018 & -.055 & .957 \\
\hline & D1.IOS & .006 & .020 & .237 & .324 & .748 \\
\hline & D2.FCF & -.008 & .066 & -.030 & -.119 & .906 \\
\hline & D2.FIN & .009 & .005 & .677 & 1.804 & .080 \\
\hline & D2.IOS & .014 & .021 & .482 & .680 & .501 \\
\hline & D3.FCF & .151 & .130 & .244 & 1.160 & .254 \\
\hline & D3.FIN & .001 & .004 & .105 & .299 & .766 \\
\hline & D3.IOS & .015 & .023 & .396 & .625 & .536 \\
\hline & D4.FCF & .034 & .059 & .234 & .579 & .566 \\
\hline & D4.FIN & .002 & .004 & .182 & .530 & .600 \\
\hline & D4.IOS & .014 & .022 & .414 & .617 & .541 \\
\hline
\end{tabular}

a. Dependent Variable: EM

Sumber : hasil olah data 
Tabel 3. Hasil Uji Asumsi Klasik

\begin{tabular}{|c|c|c|c|c|c|}
\hline \multirow{2}{*}{\multicolumn{2}{|c|}{ Jenis Pengujian }} & \multicolumn{3}{|c|}{ Variabel } & \multirow[t]{2}{*}{ Keterangan } \\
\hline & & FCF & FIN & IOS & \\
\hline Normalitas & & \multicolumn{3}{|c|}{ Asymp. Sig (2-tailed) $=0,001$} & $\begin{array}{l}\text { Central Limit Theorem } n>30 \\
=\text { berdistribusi normal }\end{array}$ \\
\hline \multirow{2}{*}{$\begin{array}{l}\text { Multikolineari } \\
\text { tas }\end{array}$} & Tol & 0,987 & 0,839 & 0,845 & \multirow{2}{*}{$\begin{array}{l}\text { Tidak terdapat } \\
\text { multikolinearitas }\end{array}$} \\
\hline & VIF & 1,013 & 1,192 & 1,183 & \\
\hline Autokorelasi & & \multicolumn{3}{|c|}{ Durbin Watson $=2,284$} & Tidak terdapat autokorelasi \\
\hline Heteroskedasti & & 0,056 & 0,570 & 0,674 & $\begin{array}{l}\text { Tidak terdapat } \\
\text { heteroskedastisitas }\end{array}$ \\
\hline
\end{tabular}

Tabel 4. Hasil Uji F, Uji t, dan Koefisien Determinasi

\begin{tabular}{|c|c|c|c|c|c|}
\hline Jenis Pengujian & Kriteria & Variabel & Sig & Koefisien & Hasil \\
\hline Uji F & Sig < 0,05 & $\begin{array}{c}\text { FCF, } \\
\text { FIN, IOS }\end{array}$ & 0,035 & & $\begin{array}{l}\text { Secara } \\
\text { bersamaan } \\
\text { variabel } \\
\text { independen } \\
\text { berpengaruh } \\
\text { terhadap } \\
\text { variabel } \\
\text { dependen }\end{array}$ \\
\hline \multirow[t]{3}{*}{ Uji t } & Sig $<0,05$ & FCF & $\begin{array}{c}0,072 \\
\quad / 2 \\
=0,03 \\
6 \\
\end{array}$ & 0,026 & Terima Ha \\
\hline & & FIN & $\begin{array}{c}0,483 \\
12 \\
=0,24 \\
15 \\
\end{array}$ & $-0,001$ & Terima Ho \\
\hline & & IOS & $\begin{array}{c}0,050 \\
12 \\
=0,02 \\
5\end{array}$ & 0,009 & Terima Ha \\
\hline $\begin{array}{l}\text { Koefisien } \\
\text { Determinasi } \\
\text { umber : hasil olah }\end{array}$ & Nilai R Squa & besar 0,15 & $t=15,4$ & & \\
\hline
\end{tabular}

